\title{
HUBUNGAN KELINCAHAN, KECEPATAN, DAN KESEIMBANGAN DENGAN KETERAMPILAN MENGGIRING BOLA PEMAIN SEPAKBOLA UNIVERSITAS BINA DARMA
}

\author{
M. Haris Satria ${ }^{1}$ \\ Bangkit Seandi Taroreh ${ }^{2}$ \\ Universitas Bina Darma \\ haris@binadarma.ac.id, $\underline{\text { bangkitseanditaroreh@binadarma.ac.id }}$
}

\begin{abstract}
Abstrak
Penelitian ini bertujuan untuk mengetahui hubungan kelincahan, kecepatan, dan keseimbangan dengan menggiring bola pemain sepakbola Universitas Bina Darma. Metode yang digunakan dalam penelitian ini menggunakan desain korelasi (Correlational Design) dengan jumlah sampel 17 orang siswa. Populasi dalam penelitian ini yaitu seluruh pemain sepakbola Bina Darma berjumlah 17 orang dan sampel dalam penelitian ini berjumlah 17 orang. Instrumen tes dalam penelitian ini yaitu dogging run, lari 40 meter, modified bass test of dynamic balance, dan menggiring bola. Teknik analisis data menggunakan SPSS statistik 23. Hasil penelitian menunjukkan terdapat hubungan kelincahan dengan menggiring bola $(0.019<0.005)$, terdapat hubungan kecepatan dengan menggiring bola $(0.027<0.005)$, terdapat hubungan keseimbangan dengan menggiring bola $(0.001<0.005)$, dan terdapat hubungan kelincahan, kecepatan dan keseimbangan dengan menggiring bola, nilai $F_{\text {hitung }}=22,35>F_{\text {tabel }}=3,411$.
\end{abstract}

Kata kunci: kelincahan, kecepatan, keseimbangan, menggiring bola

\begin{abstract}
This study aims to determine the correlation between agility, speed, and balance by dribbling University Bina Darma football players. The method used in this study uses a correlation design (correlation design) with a sample of 17 students. The population in this study were all Bina Darma football players totaling 17 people and the sample in this study amounted to 17 people. The instruments in this research used dogging run, 40 meter run, modified bass test of dynamic balance, and dribbling. Data analysis techniques using SPSS statistics 23. The results showed that there was have a correlation of agility with dribbling $(0.019<0.005)$, there was a correlation speed with dribbling $(0.027<0.005)$, have a correlation balance with dribbling $(0.001<0.005)$, and have a correlation agility, speed and balance with dribbling, $F$ count $=22.35>$ Ftable $=3.411$.
\end{abstract}

Keywords : agility, speed, balance, dribling

Dipublikasikan Oleh :

UPT Publikasi dan Pengelolaan Jurnal

Universitas Islam Kalimantan Muhammad Arsyad Al-Banjari Banjarmasin 


\section{PENDAHULUAN}

Sepakbola merupakan olahraga permainan yang dimainkan oleh dua tim dengan tujuan memasukkan bola ke dalam gawang. Muhajir (2004:1) mengatakan bahwa sepakbola adalah suatu permainan yang dilakukan dengan jalan menyepak bola, dengan tujuan memasukan bola ke gawang lawan dan mempertahankan gawang tersebut agar tidak kemasukkan bola. Seseorang dapat bermain sepakbola dengan baik ketika seseorang menguasai teknik dasar bermain sepakbola dengan baik pula. Teknik dasar sepakbola yaitu meliputi aktivitas mengoper, menembak, menggiring bola, mengontrol dan menyundul bola. Hal ini sejalan dengan pendapat Mielke (2007:1) yang menyatakan bahwa kemampuan dasar bermain sepakbola yang harus dikuasai antara lain adalah menggiring (dribbling), mengoper (passing), menembak (shooting), menyundul bola (heading), menimang bola (juggling), menghentikan bola (trapping), dan lemparan ke dalam (throw-in).

Dari teknik dasar di atas salah satu teknik yang sangat penting untuk dikuasai oleh pemain sepakbola yaitu kemampuan menggiring bola (dribling). Ketika seorang pemain memiliki kemampuan menggiring bola yang baik maka pemain akan sangat mudah untuk melewati mawan, merubah area permainan, mengatur tempo permainan dan memudahkan untuk masuk ke jantung pertahanan musuh sehingga kesempatan untuk memenangkan pertandingan akan sangat terbuka. Kemampuan menggiring bola yang baik, tidak terlepas dari kemampuan biomotorik manusia. Kemampuan biomotorik manusia yang dominan untuk menggiring bola dalam sepakbola yaitu meliputi kelincahan, kecepatan dan keseimbangan. Jadi, menggiring bola berkaitan erat dengan ketiga komponen tersebut.

Kelincahan adalah kemampuan mengubah arah atau posisi tubuh dengan cepat yang dilakukan bersama-sama dengan gerak lainnya (Widiyastuti, 2015: 137). Menurut Subardjah (2012: 11) kelincahan adalah kemampuan seorang atlet untuk dapat mengubah arah dengan cepat dan pada waktu bergerak tanpa kehilangan keseimbangan. Dari dua pendapat di atas dapat ditarik kesimpulan bahwa kelincahan merupakan kemampuan seseorang untuk merubah arah dengan cepat dan tepat dimana pada saat yang bersamaan dilakukan gerakan lain tanpa mengalami kehilangan keseimbangan.

Menurut Sukadiyanto (2010:144) kecepatan adalah kemampuan seseorang untuk melakukan gerak atau serangkaian gerak secepat mungkin sebagai jawaban terhadap rangsang. Dengan kata lain kecepatan merupakan kemampuan seseorang untuk menjawab rangsang dengan bentuk gerak atau serangkaian gerak dalam waktu secepat mungkin. Arah latihan kecepatan mencakup arah ke depan, belakang, samping (kanan-kiri) sedangkan jarak relatif pendek. Untuk jarak dan bentuk latihan kecepatan adalah pendek-pendek dan terputus-putus dengan arah yang berganti-ganti secara mendadak.

Selanjutnya menurut Widiastuti (2015:161) keseimbangan adalah kemampuan mempertahankan sikap dan posisi tubuh secara tepat pada saat berdiri (static balance) atau pada saat melakukan gerakan (dynamic balance). Setiap orang sangat meerlukan keseimbangan untuk dapat mempertahankan stabilitas posisi tubuh dalam kondisi statik maupun dinamik. Dalam melaksanakan tugas sehari-hari ataupun dalam melakukan aktivitas keolahragaan keseimbangan sangat dibutuhkan.

Berangkat dari latar belakang di atas maka peneliti tertarik untuk melakukan sebuah penelitian mengenai kemampuan menggiring bola pemain sepakbola Universitas Bina Darma. Adapun judul penelitian yang akan diangkat adalah hubungan kelincahan, kecepatan dan keseimbangan dengan kemampuan menggiring bola pemain sepakbola Universitas Bina Darma. Harapananya penelitian ini berkontribusi untuk perkembangan olahraga di Indonesia pada umumnya dan Bina Darma khususnya.

\section{METODE PENELITIAN}

\section{Jenis Penelitian}

Penelitian ini merupakan jenis penelitian kuantitatif dengan pendekatan korelasional. Metode yang digunakan dalam penelitian ini adalah metode korelasional yang bertujuan untuk mengetahui ada atau tidak adanya hubungan, apabila ada seberapa eratnya serta berarti atau tidaknya (Arikunto, 2010:203).

Dipublikasikan Oleh : 


\section{Rancangan Penelitian}

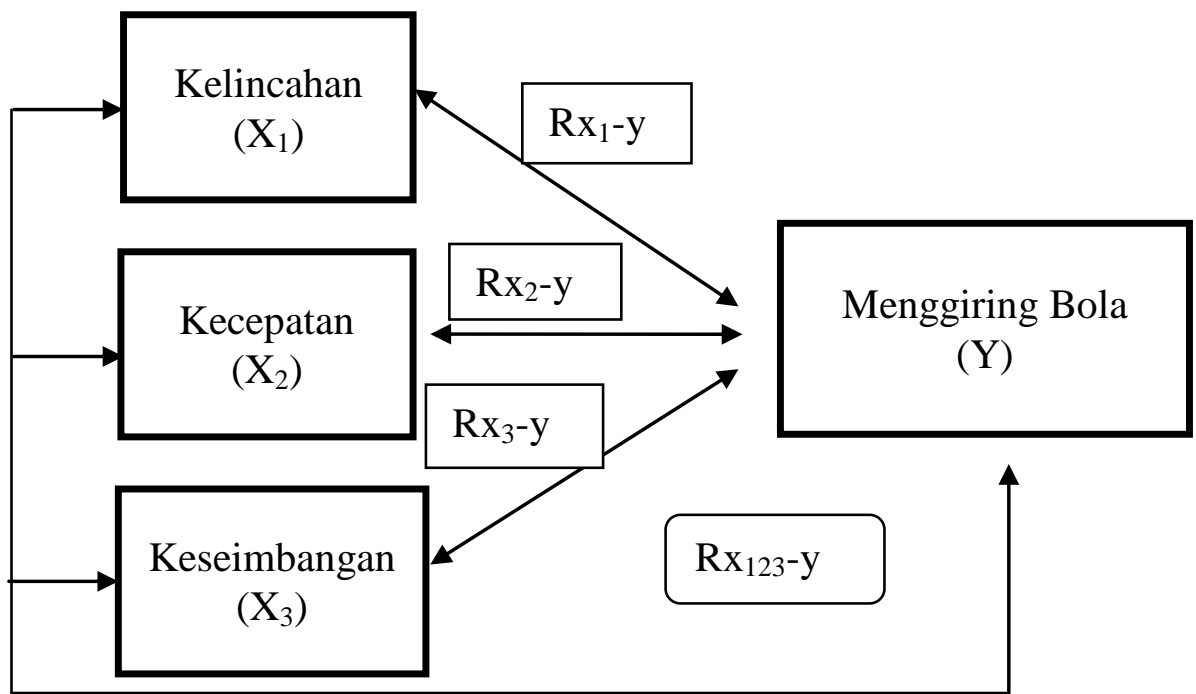

Gambar 1. Rancangan Penelitian

(Sumber: Sugiyono, 2012)

\section{Keterangan:}

$\mathrm{X}_{1}=$ Kelincahan

$\mathrm{X}_{2}=$ Kecepatan

$\mathrm{X}_{3}=$ Keseimbangan

$\mathrm{Y}=$ Menggiring Bola

$\mathrm{X}_{1}$ dan $\mathrm{Y}=$ Hubungan Kelincahan dengan Kemampuan Menggiring Bola

$\mathrm{X}_{2}$ dan $\mathrm{Y}=$ Hubungan Kecepatan dengan Kemampuan Menggiring Bola

$\mathrm{X}_{3}$ dan $\mathrm{Y}=$ Hubungan Keseimbangan dengan Kemampuan Menggiring Bola

$\mathrm{X}_{1} \mathrm{X}_{2} \mathrm{X}_{3}$ dan $\mathrm{Y}=$ Hubungan Kelincahan, Kecepatan, dan Keseimbangan dengan Kemampuan Menggiring Bola

\section{Tempat Dan Waktu Penelitian}

Penelitian dilakukan di lapangan Sekolah Olahraga Negeri Sriwijaya (SONS). Sumatera Selatan Waktu penelitian dilakukan hari Jum'at, Sabtu dan Minggu pada pukul 16.00 WIB - 18.00 WIB.

\section{Populasi dan Sampel}

Populasi adalah keseluruhan subjek penelitian. Adapun yang menjadi populasi dalam penelitian ini adalah peserta sekolah sepak bola Senuro. Populasi adalah keseluruhan subjek penelitian, (Arikunto, 2006: 130). Keseluruhan yang menjadi sasaran dalam penelitian ini adalah pemain sepakbola Universitas Bina Darma yang berjumlah 17 orang. Arikunto (2006: 131) mengatakan bahwa sampel adalah sebagian atau wakil populasi yang diteliti. "Untuk sekedar ecer-ecer, maka apabila subjeknya kurang dari 100, maka lebih baik diambil semua sehingga penelitiannya merupakan penelitian populasi. Tetapi, jika jumlah subjeknya besar, dapat diambil antara $10-15 \%$ atau $20-25 \%$ atau lebih".

Berdasarkan pendapat ahli di atas maka sampel yang diambil dalam penelitian ini adalah pemain sepakbola Universitas Bina Darma yang berjumlah 17 orang. 


\section{Instrumen Tes}

Instrument penelitian adalah suatu alat yang digunakan mengukur fenomena alam maupun sosial yang diamati (Sugiyono, 2012: 148). Instrumen tes yang digunakan dalam penelitian ini meliputi :

1. Kelincahan menggunakan dogging run (Widiastuti, 2008:142).

2. Kecepatan menggunakan tes lari cepat 40 meter (Widiastuti, 2015:126).

3. Keseimbangan menggunakan Modified Bass Test of Dynamic Balance (Widiastuti, 2015:164)

4. Menggiring bola menggunakan tes menggiring bola melewati cone satu ke cone lainnya dan kembali ke cone awal. (Nurhasan, 2007:161)

\section{Hipotesis Penelitian}

Hipotesis merupakan jawaban sementara. Berikut adalah hipotesis dalam penelitian ini yaitu :

1. Terdapat hubungan antara kelincahan dengan kemampuan menggiring bola pemain sepakbola Universitas Bina Darma.

2. Terdapat hubungan antara kecepatan dengan kemampuan menggiring bola pemain sepakbola Universitas Bina Darma

3. Terdapat hubungan antara keseimbangan dengan kemampuan menggiring bola pemain sepakbola Universitas Bina Darma

4. Terdapat hubungan antara kelincahan, kecepatan dan keseimbangan dengan kemampuan menggiring bola pemain sepakbola Universitas Bina Darma.

Teknik Analisis Data statistic 23 .

Teknik analisis data dalam penelitian ini yaitu uji t (t-test). Uji t tersebut menggunakan SPSS

\section{HASIL DAN PEMBAHASAN}

\section{Penyajian Data Kelincahan $\left(X_{1}\right)$, Kecepatan $\left(X_{2}\right)$, Keseimbangan $\left(X_{3}\right)$ dan Menggiring Bola $(Y)$}

Berikut adalah penyajian data hasil penelitian yang dilakukan terhadap 17 pemain sepakbola Universitas Bina Darma. Untuk lebih jelasnya dapat dilihat pada tabel di bawah ini :

Tabel 1.

Data Hasil Penelitian

\begin{tabular}{|c|c|c|c|c|c|}
\hline \multirow{2}{*}{ No. } & \multirow{2}{*}{ Nama } & $\begin{array}{c}\text { Kelincahan } \\
\left(\mathbf{X}_{\mathbf{1}}\right)\end{array}$ & $\begin{array}{c}\text { Kecepatan } \\
\left(\mathbf{X}_{\mathbf{1}}\right)\end{array}$ & $\begin{array}{c}\text { Keseimbangan } \\
\left(\mathbf{X}_{\mathbf{1}}\right)\end{array}$ & $\begin{array}{c}\text { Menggiring Bola } \\
(\mathbf{Y})\end{array}$ \\
\cline { 3 - 6 } & $($ detik$)$ & $($ detik$)$ & $($ detik$)$ & $($ detik$)$ \\
\hline 1 & $\mathrm{X} 1$ & 15,21 & 06,37 & 16,26 & 17,30 \\
\hline 2 & $\mathrm{X} 2$ & 15,30 & 06,21 & 17,04 & 18,42 \\
\hline 3 & $\mathrm{X} 3$ & 14,76 & 05,39 & 16,56 & 19,08 \\
\hline 4 & $\mathrm{X} 4$ & 15,03 & 06,76 & 18,36 & 18,23 \\
\hline 5 & $\mathrm{X} 5$ & 14,12 & 05,41 & 15,45 & 17,57 \\
\hline 6 & $\mathrm{X} 6$ & 15,07 & 06,20 & 11,58 & 19,34 \\
\hline 7 & $\mathrm{X} 7$ & 15,34 & 06,43 & 17,10 & 18,12 \\
\hline 8 & $\mathrm{X} 8$ & 14,21 & 05,72 & 19,38 & 17,13 \\
\hline 9 & $\mathrm{X} 9$ & 14,17 & 05,11 & 20,21 & 17,09 \\
\hline 10 & $\mathrm{X} 10$ & 16,09 & 07,46 & 18,23 & 18,14 \\
\hline 11 & $\mathrm{X} 11$ & 15,32 & 06,34 & 17,32 & 18,03 \\
\hline 12 & $\mathrm{X} 12$ & 14,21 & 06,05 & 16,43 & 18,50 \\
\hline
\end{tabular}

Dipublikasikan Oleh : 


\begin{tabular}{|l|l|l|l|l|l|}
13 & $\mathrm{X} 13$ & 16,10 & 08,12 & 17,35 & 19,04 \\
\hline 14 & $\mathrm{X} 14$ & 13,26 & 04,23 & 22,30 & 17,03 \\
\hline 15 & $\mathrm{X} 15$ & 14,23 & 05,51 & 16,56 & 18,45 \\
\hline 16 & $\mathrm{X} 16$ & 14,45 & 05,11 & 17,45 & 18,37 \\
\hline 17 & $\mathrm{X} 17$ & 16,28 & 08,53 & 13,02 & 19,17 \\
\hline
\end{tabular}

\section{Korelasi SederhanaKelincahan Dengan Menggiring Bola $\left(X_{1}\right.$ Dengan $\left.Y\right)$}

Hasil analisis menunjukkan bahwa kelincahan memiliki korelasi yang signifikan dengan kemampuan menggiring bola. Hasil tersebut dapat dilihat dari perhitungan statistik dimana taraf signifikannya adalah $\quad(0.019<0.005)$. untuk lebih jelasnya dapat dilihat pada tabel di bawah ini :

Tabel 2.

Korelasi Sederhana Kelincahan dengan Menggiring Bola

Correlations

\begin{tabular}{|ll|r|r|}
\hline & & MenggiringBol \\
\hline Kelincahan & Pearson Correlation & 1 & $.563^{*}$ \\
& Sig. (2-tailed) & & .019 \\
& $\mathrm{~N}$ & 17 & 17 \\
\hline Menggiringbola & Pearson Correlation & $.563^{*}$ & 1 \\
& Sig. (2-tailed) & .019 & 17 \\
& $\mathrm{~N}$ & 17 & \\
\end{tabular}

*. Correlation is significant at the 0.05 level (2-tailed).

Korelasi SederhanaKecepatan Dengan Menggiring Bola $\left(\mathbf{X}_{2}\right.$ Dengan $\left.Y\right)$

Hasil analisis menunjukkan bahwa kelincahan memiliki korelasi yang signifikan dengan kemampuan menggiring bola. Hasil tersebut dapat dilihat dari perhitungan statistik dimana taraf signifikannya adalah $\quad(0.027<0.005)$. untuk lebih jelasnya dapat dilihat pada tabel di bawah ini :

Tabel 3.

Korelasi Sederhana Kecepatan dengan Menggiring Bola

Correlations

\begin{tabular}{|ll|r|r|}
\hline & & kecepatan & menggiringbola \\
\hline Kecepatan & Pearson Correlation & 1 & $.534^{*}$ \\
& Sig. (2-tailed) & & .027 \\
& $\mathrm{~N}$ & 17 & 17 \\
\hline Menggiringbola & Pearson Correlation & $.534^{*}$ & 1 \\
& Sig. (2-tailed) & .027 & 17 \\
& $\mathrm{~N}$ & 17 & 17 \\
\hline
\end{tabular}

*. Correlation is significant at the 0.05 level (2-tailed).

\section{Korelasi SederhanaKeseimbangan Terhadap Menggiring Bola $\left(X_{3}\right.$ Dengan $\left.Y\right)$}

Hasil analisis menunjukkan bahwa kelincahan memiliki korelasi yang signifikan dengan kemampuan menggiring bola. Hasil tersebut dapat dilihat dari perhitungan statistik dimana taraf signifikannya adalah $\quad(0.001<0.005)$. untuk lebih jelasnya dapat dilihat pada tabel di bawah ini :

Tabel 4.

Korelasi Sederhana Keseimbangan dengan Menggiring Bola Correlations

Dipublikasikan Oleh :

UPT Publikasi dan Pengelolaan Jurnal

Universitas Islam Kalimantan Muhammad Arsyad Al-Banjari Banjarmasin 


\begin{tabular}{|ll|r|r|}
\hline Keseimbangan & Pearson Correlation & 1 & $-.717^{* *}$ \\
& Sig. (2-tailed) & & .001 \\
& $\mathrm{~N}$ & 17 & 17 \\
\hline Menggiringbola & Pearson Correlation & $-.717^{* *}$ & 1 \\
& Sig. (2-tailed) & .001 & \\
& $\mathrm{~N}$ & 17 & 17 \\
\hline
\end{tabular}

**. Correlation is significant at the 0.01 level (2-tailed).

Korelasi SederhanaKelincahan, Kecepatan, danKeseimbangan Terhadap Menggiring Bola $\left(\mathbf{X}_{3}\right.$ Dengan Y)

Hasil analisis menunjukkan bahwa kelincahan memiliki korelasi yang signifikan dengan kemampuan menggiring bola. Hasil tersebut dapat dilihat dari perhitungan statistik dimana taraf signifikannya adalah $\quad(0.000<0.005)$. untuk lebih jelasnya dapat dilihat pada tabel di bawah ini :

Tabel 2.

Korelasi Sederhana Kelincahan, Kecepatan dan Keseimbangan dengan Menggiring Bola

Correlations

\begin{tabular}{|c|c|c|c|c|c|}
\hline \multicolumn{3}{|c|}{ Control Variables } & Kelincahan & Kecepatan & Keseimbangan \\
\hline \multirow[t]{3}{*}{ Menggiringbola } & Kelincahan & $\begin{array}{l}\text { Correlation } \\
\text { Significance (2-tailed) } \\
\text { df }\end{array}$ & $\begin{array}{r}1.000 \\
. \\
0\end{array}$ & $\begin{array}{r}.895 \\
.000 \\
14 \\
\end{array}$ & $\begin{array}{r}.366 \\
.163 \\
14 \\
\end{array}$ \\
\hline & Kecepatan & $\begin{array}{l}\text { Correlation } \\
\text { Significance (2-tailed) } \\
\text { df }\end{array}$ & $\begin{array}{r}.895 \\
.000 \\
14\end{array}$ & $\begin{array}{r}1.000 \\
. \\
0\end{array}$ & $\begin{array}{r}.429 \\
.097 \\
14\end{array}$ \\
\hline & $\overline{\text { Keseimbangan }}$ & $\begin{array}{l}\text { Correlation } \\
\text { Significance (2-tailed) } \\
\text { df }\end{array}$ & $\begin{array}{r}.366 \\
.163 \\
14\end{array}$ & $\begin{array}{r}.429 \\
.097 \\
14\end{array}$ & 1.000 \\
\hline
\end{tabular}

\section{PENUTUP}

\section{Kesimpulan}

Berdasarkan hasil penelitian dalam penelitian ini, maka kesimpulan dalam penelitian ini, yaitu :

1. Terdapat hubungan yang signifikan antara kelincahan dengan menggiring bola dengan taraf signifikannya adalah $(0.019<0.005)$.

2. Terdapat hubungan yang signifikan antara kelincahan dengan menggiring bola dengan taraf signifikannya adalah $(0.027<0.005)$.

3. Terdapat hubungan yang signifikan antara kelincahan dengan menggiring bola dengan taraf signifikannya adalah $(0.001<0.005)$.

4. Terdapat hubungan yang signifikan antara kelincahan dengan menggiring bola dengan nilai $\mathrm{F}_{\text {hitung }}=22,35>\mathrm{F}_{\text {tabel }}=3,411$.

\section{Saran} yaitu :

Berdasarkan simpulan dalam penelitian ini, maka saran yang dapat peneliti rekomendasikan

1. Bagi guru, dosen terutama untuk pelatih agar dalam latihan dapat memperhatikan komponen biomotorik manusia yang terdiri dari unsur kelincahan, kecepatan, dan keseimbangan dalam upaya meningkatkan keterampilan menggiring bola sepakbola bagi pemain/ atlet.

2. Perlunya penelitian lanjutan dari penelitian ini dan memperbanyak sampel juga variabel yang lebih luas, agar diperoleh gambaran secara komprehensif dan mendalam tentang kemampuan menggiring bola.

Dipublikasikan Oleh :

UPT Publikasi dan Pengelolaan Jurnal

Universitas Islam Kalimantan Muhammad Arsyad Al-Banjari Banjarmasin 


\section{DAFTAR PUSTAKA}

Arikunto, Suharsimi. 2006. Prosedur Penelitian Suatu Pendekatan. Rineka Cipta. Jakarta.

Arikunto, Suharsimi. 2010. Prosedur Penelitian. Jakarta: Rineka Cipta.

Meilke, Danny. 2007. Dasar - Dasar Sepakbola. PT Intan Sejati. Bandung.

Muhajir. 2004. Pendidikan Jasmani Teori dan praktik SMA Kelas X. Jakarta : Erlangga.

Subardjah, H. (2012). Latihan Fisik. Bandung: Fakultas Pendidikan Olahraga dan Kesehatan Universitas Pendidikan Indonesia.

Sugiyono, 2012. Metode Penelitian Pendidikan Pendekatan Kuantitatif, Kualitatif dan R\&D. CV Alfabeta. Bandung.

Sukadiyanto. 2010. Metodologi Melatih Fisik. Universitas Negeri Yogyakarta. Yogyakarta

Widiastuti. 2015. Tes dan Pengukuran Olahraga. Jakarta: Rajawali Pers.

Dipublikasikan Oleh : 